\title{
Put me in, Coach, I'm ready to play
}

\author{
Christopher J. Coyne • Justin P. Isaacs • \\ Jeremy T. Schwartz • Anthony M. Carilli
}

Published online: 25 August 2007

(C) Springer Science + Business Media, LLC 2007

\begin{abstract}
This paper explores the connection between discrimination and entrepreneurship. To pursue this inquiry we focus on the integration of black players in Major League Baseball (MLB). MLB team owners, acting as entrepreneurs, had to weigh the benefits of integrating versus the costs of alienating consumers who had a taste for discrimination against hiring blacks. We find that the owners whose teams could profit by contending for the league pennant with the addition of black players were the ones who were willing to take the risk of integrating, although integration often stood in contrast to revealed consumer preferences. In addition to illuminating the mechanism through which integration took place, we offer a general understanding of how the costs and benefits associated with consumers' taste for discrimination can change via entrepreneurial activities.
\end{abstract}

Keywords Entrepreneurship · Discrimination · Sports economics

JEL codes $\mathrm{B} 53 \cdot \mathrm{L} 83 \cdot \mathrm{M} 13$

\section{Introduction}

In The Economics of Discrimination, Gary Becker (1957) identified three forms of discrimination: employer, co-worker, and consumer discrimination. Becker concluded that employers who discriminated would incur the full cost of engaging in discrimination by

C. J. Coyne $(\bowtie)$

Department of Economics, West Virginia University, Morgantown, WV 26506-6025, USA

e-mail: chris.coyne@mail.wvu.edu

J. P. Isaacs $\cdot$ J. T. Schwartz $\cdot$ A. M. Carilli

Department of Economics, Hampden-Sydney College, Hampden-Sydney, VA 23943, USA

J. P. Isaacs

e-mail: jisaacs@hsc.edu

J. T. Schwartz

e-mail: jschwartz@hsc.edu

A. M. Carilli

e-mail: tcarilli@hsc.edu 
failing to employ the most productive workers. Given this, discriminating employers would ultimately be driven out of business because of the fact that a non-discriminating employer can increase productivity and minimize costs, ceteris paribus. Along similar lines, within Becker's model, one would expect that markets would erode co-worker discrimination, as equally competitive firms will provide equal pay for equal work.

The third form of discrimination identified by Becker is consumer discrimination, which entails discrimination by the consumers of the products and services of firms. Although employer and co-worker discrimination will tend to be eliminated by the competitive forces of the market, consumer discrimination may potentially persist over the long run. This is because of the fact that firms that meet consumer preferences for discrimination will be rewarded by customers who demand discrimination as part of the bundle of goods and services offered by firms. As a result, unlike employer and co-worker discrimination, competitive market forces are less likely to mitigate problems stemming from consumer discrimination.

In reality, all three forms of discrimination identified by Becker may exist in the market at any point in time. Actual markets, unlike Becker's perfectly competitive model, are characterized by imperfect competition and imperfect information. As such, inefficiencies may not only exist, but persist over time (Leeson et al. 2006). Given this, the central issue becomes the mechanisms through which these inefficiencies are best recognized and corrected. One of the main contributions of the Austrian school of economics is the recognition of the entrepreneur as the means through which market inefficiencies are corrected (see Kirzner 1973). While the three forms of discrimination identified by Becker may indeed exist in markets, entrepreneurs will tend to be alert to these potential profit opportunities and will tend to exploit them. In short, while discrimination is never completely eradicated in markets, there is a tendency for the correction of such inefficiencies.

In this paper, we explore the connection between discrimination and entrepreneurship. While those writing in the Austrian tradition have focused on the ethical side of the discrimination issue (Block 1998), there has been a lack of attention paid to discrimination in the market process. To pursue this line of inquiry, we focus on the integration of black players in Major League Baseball (MLB). As Shmanske (2007) points out, sports economics offers a large amount of clean and objective data that can be used to illuminate the Austrian theory of entrepreneurship. Along similar lines, Kahn (2000) highlights that sports serves as a laboratory to study labor markets. As such, analyzing the integration of black players into MLB is a straightforward means of understanding how entrepreneurs correct inefficiencies associated with the three forms of discrimination identified by Becker.

The contribution of this paper is twofold. First, it can be seen as contributing to an existing literature exploring the integration of black players in MLB. For instance, Gwartney and Haworth (1974) focus on the impact that the integration of black players had on major league teams. They find that integration had a positive effect on wins and attendance. Hanssen (1998) builds on the work of Gwartney and Haworth by examining the degree to which integration occurred from 1950 to 1984 . Our contribution to this existing literature is to elucidate the mechanism through which integration took place. The integration of black players into MLB can be seen as an entrepreneurial action entailing alertness and exploitation of a profit opportunity - in this case, competing for the league pennant. MLB entrepreneurs would integrate and risk alienating their consumers only if they believed that doing so would help their team reach the World Series, a result that consumers preferred over discrimination. In addition to contributing to this existing literature on integration in MLB, this paper can simultaneously be seen as an attempt to further Shmanske's (2007) effort to provide empirical support for the Austrian theory of entrepreneurship. In doing so, we also elucidate the connection between entrepreneurship, the market process, and discrimination. 
We proceed as follows. In the next section, we explore the theoretical connection between entrepreneurship and discrimination. In doing so, we explain how entrepreneurs, through their alertness to profit opportunities, continually correct the inefficiencies associated with discrimination. In Section III we use empirical data to illuminate these theoretical claims. Specifically, we show that teams who hired black players beginning in 1947 were motivated by the belief that such players would help the team compete for the league pennant. Teams whose relative performance within the league was unlikely to be improved by hiring black players chose not to integrate. Section IV concludes.

\section{Discrimination and the entrepreneurial process}

Kirzner's (1973) theory of entrepreneurship emphasizes the alertness to profit opportunities. Acting on perceived profit opportunities, entrepreneurs serve the dual role of pushing the economy toward the production possibility frontier and shifting the frontier outward (an increase in real output due to an increase in real productivity). In short, yesterday's inefficiencies are today's profit opportunities and, in exploiting those opportunities, entrepreneurs serve as the catalyst of economic change.

Every economic action has an element of entrepreneurship to it. Economic decision makers do not simply react to given data and allocate their scarce means to realize given ends. The entrepreneurial element in human action entails the discovery of new data and information, discovering anew not only the appropriate means, but also the ends that are to be pursued. As such, entrepreneurs are the central mechanism through which market inefficiencies are corrected. Of course, market inefficiencies are never completely eradicated, but entrepreneurs, acting within an environment characterized by property, prices, and profit and loss, are the most effective means for correcting existing errors.

How does entrepreneurial alertness relate to the three forms of discrimination identified by Becker? Over time, we would expect entrepreneurs to exploit the profit opportunities created by employer and co-worker discrimination. In short, entrepreneurs, once they are aware of the opportunity, will act to profit by employing resources that are cast aside by others due to discrimination. These resources reflect profit opportunities because they provide an opportunity to increase productivity leading to more efficient production, and hence greater profit, compared to the firms that choose to engage in discrimination. Ultimately, there will be a tendency toward market segmentation by discriminating and nondiscriminating firms, with the latter gaining the upper hand in the market competition. To reiterate, given imperfect information and imperfect competition, this is not an instantaneous process. Instead, the market process tends to eradicate inefficiencies associated with employer and co-worker discrimination.

Consumer discrimination is more problematic because, as discussed in the "Introduction", consumers reward producers for satisfying their preferences of discrimination. In other words, consumers reward producers for continuing to engage in discrimination, and firms, responding to the profit motive, continue to satiate this demand. The end result is, in theory, the persistence of the inefficiencies associated with discrimination. At first blush, it appears that consumer discrimination fails to be self-correcting as the case of employer and coworker discrimination. However, just as entrepreneurs are central in overcoming employer and co-worker discrimination, they also play a key role in overcoming the inefficiencies associated with consumer discrimination.

A central part of the entrepreneurial process is revealing the latent demands of consumers. For instance, advertising plays a key role in the market process by reducing the 
information costs associated with introducing new products and services (see Ekelund and Saurman 1988). Through this process, consumers become increasingly informed about the costs associated with their tastes.

While entrepreneurs attempt to meet existing consumer preferences, they simultaneously attempt to meet latent demands as well. Introducing a product or services that consumers were not previously aware of is one example of this. Entrepreneurs are not passive actors who simply respond to revealed consumer preferences, but constantly attempt to meet both revealed and latent demands. In the context of discrimination, if entrepreneurs can demonstrate to consumers the costs associated with their taste for discrimination, consumers will tend to change their behavior accordingly. In short, entrepreneurs have the ability to influence consumer behavior and social norms through innovation just as they have the ability to innovate in the realm of goods and services.

The case of integration in MLB is a perfect illustration of the process described above. In the context of baseball, integration can be seen as an innovation, which ultimately contributed to a change in consumer behavior toward black players. Consumers had revealed a preference for winning as evidenced by increases in game attendance when their teams won more games (Hanssen 1998). Further, consumers revealed a preference for teams that not only won more games, but also competed for the pennant. In other words, profits were directly attached to winning and competing for a pennant. Given this, the MLB owners, acting in an entrepreneurial manner, had to determine the best means to maximize profits. This included determining the best mix of players that maximized the chances of victory.

Some owners realized that the integration of black players to their teams would provide them with a competitive advantage over others. Owners had to weigh the expected benefits of integrating versus the expected costs of alienating consumers who had a taste for discrimination against hiring blacks. In other words, owners who chose to integrate had to assemble a winning team to offset the potential losses from consumer discrimination against black players. Indeed, Goff et al. (2002) view integration as an economic innovation that allowed owners to reorganize their 'firm' in a more productive manner. This interpretation fits well with the Austrian theory of entrepreneurship.

In addition to increasing efficiency, integration also contributed to the shift in consumer behaviors away from discrimination against black players. If, as Hanssen suggested, there was a taste for discrimination among consumers, one should only expect those cases where integration allowed a team to meet this revealed demand for pennant competition to be welcomed by fans. MLB owners who were alert to the benefits of integration for increasing wins also had the effect of shifting consumer behavior by raising the cost of continuing to engage in discriminatory behavior.

Along these lines, Branch Rickey and Bill Veeck were the first movers who were alert to the profit opportunities tied to integration in MLB. Rickey was the President of the National League's (NL) Brooklyn Dodgers who hired Jackie Robinson, first to a minor league contract in 1945 and then for the Dodgers in 1947. Veeck, the owner of the American League's (AL) Cleveland Indians, followed suit shortly thereafter by hiring Larry Doby as an outfielder and Satchel Paige as a pitcher. It should come as no surprise that these two men were the first to break the "color line." Both men were renowned for their innovations to the game of baseball well before integration in 1947. Branch Rickey, dissatisfied with continually losing promising young talent to wealthier teams like the New York Giants, began buying minor league teams as a way to keep young talent in the organization. This became baseball's first "farm system." Rickey was also the first owner to train batters with a pitching machine, and the first owner to build a complex in Florida where all members of the organization could train (Leeds and von Allmen 2005). 
While Rickey was famous for creating winning teams, Bill Veeck was famous for his ability to use innovation as a way to bring fans into the stadium. Veeck is personally responsible for names on the back of team jerseys and fireworks displays after home runs are hit. Veeck also proposed that the league use scoreboards to replay disputed calls and to inform the fans of the speed and type of pitch 20 years before they became commonly accepted practices at stadiums (Leeds and von Allmen 2005).

Why were the Dodgers and the Indians the first teams to integrate in 1947? It is important to recall that Brooklyn and Cleveland themselves were not racially integrated at the time. Cleveland, for example, had, and still has, a predominantly black population on its east side and white population on its west side. This geographical division has been the source of debate and eventual judicial activism. Henderson (2002) details the events leading to the forced busing of students from one side of Cleveland to the other in an effort to integrate, or desegregate, the public schools in the late 1970s. Clearly, the decision to integrate Cleveland's baseball team in 1947 was not in response to a consumer base with a preference for, or an acceptance of, racial integration. However, what the Dodgers and Indians did have in common was a desire to compete for their respective league pennants. Integration was one way for them to achieve this end.

\section{Empirical assessment}

\subsection{Cost of integration}

While initial integration in MLB occurred in both the NL and the AL within 5 weeks of each other, the AL integrated at a slower rate than the NL (Hanssen 1998). Hanssen attributes this difference to divergent preferences of consumers in each league. If fans in the AL held strong preferences against integration, then we would expect to see a strong backlash against the team that integrated-namely, the Cleveland Indians. Similarly, if consumers in the NL demanded integrated teams, then we would expect to see consumer support for such enlightenment.

Data was collected from The Baseball Encyclopedia and Rodney Fort's (Fort 2006) website. ${ }^{1}$ Following Gwartney and Haworth (1974), we consider MLB seasons from 1945 through 1956, although integration began in 1947. Table 1 presents attendance figures summarized for each league.

While attendance for both the Dodgers and the Indians increased immediately upon integration, overall attendance increased initially, but then tapered off over the sample period. A paired two-sample $t$ test reveals that attendance in the AL is statistically greater than that in the NL over this period, at the 5\% significance level. This would appear to support the finding that teams paid a price, in attendance terms, for employing black players (Hanssen 1998).

It is critical to remember that the entrepreneurial impact on consumer behavior is not necessarily instantaneous but rather is an ongoing process, just like adjustments in the general allocation of resources. Just as the adoption of a new technological innovation takes time, the adoption of a new behavior does as well. Integration was particularly risky for a team whose consumers (i.e., fans) showed a revealed preference for discrimination.

\footnotetext{
${ }^{1}$ We gratefully acknowledge Rodney Fort who maintains and provides the data on his website and makes it freely available.
} 
Table 1 Attendance by League, 1945-1956

\begin{tabular}{lll}
\hline Year & AL & NL \\
\hline 1945 & $5,580,420$ & $5,260,703$ \\
1946 & $9,621,182$ & $8,902,107$ \\
1947 & $9,486,069$ & $10,388,470$ \\
1948 & $11,150,099$ & $9,770,743$ \\
1949 & $10,730,647$ & $9,484,718$ \\
1950 & $9,142,361$ & $8,320,616$ \\
1951 & $8,882,674$ & $7,244,002$ \\
1952 & $8,293,896$ & $6,339,148$ \\
1953 & $6,964,076$ & $7,419,721$ \\
1954 & $7,922,364$ & $8,013,519$ \\
1955 & $8,942,971$ & $7,674,412$ \\
1956 & $7,893,683$ & $8,649,567$ \\
\hline
\end{tabular}

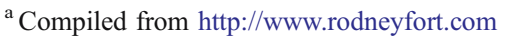

However, the important point is that the initial entrepreneurial act of integration started the process of shifting consumer behavior away from discrimination.

Hanssen (1998) shows that even though fans' taste for discrimination existed, it did not exceed their taste for winning. Specifically, Hanssen finds that for every black player on a team, annual attendance falls by approximately 9,900 fans, but in the same equation he finds that, for every game the team is behind the league leader, it loses 8,900 fans. This result is important, because if the addition of a black player leads to three additional wins a season (Gwartney and Haworth 1974), then a black player actually increases attendance. More importantly, if a team is involved in the pennant race (finished first or within five games of first place), attendance increases by 17,460 people. If the addition of a black player increases wins enough to allow a team to compete for its pennant, then the fans will accept the integration of black players despite their taste for discrimination. Stated differently, the increased wins due to integration increases the cost of discriminating leading to changes in fan behavior toward black players. However, the entrepreneurs had to be willing to bet on the outcome that integration would increase the team's wins enough to offset the potential loss due to alienating fans.

\subsection{Benefits from early adoption}

In general, if an entrepreneur correctly recognizes the latent demands of consumers, that entrepreneur should gain an advantage, at least initially, over his competitors. Ekelund and Saurman (1988) suggest that competition as a market structure breeds entrepreneurial innovation, whereas noncompetitive markets reduce it. The process of integration in MLB seems to follow a similar scenario.

The Brooklyn Dodgers won the pennant in 6 of the 10 years that Jackie Robinson played for them, and finished second three times during that period. As the Dodgers were first movers in integrating in the NL, it is not surprising that they gained an advantage by employing Robinson and other black players. The Cleveland Indians, while integrating more than any of their AL competitors, did not match the success of the Dodgers, winning the pennant only twice in the same 10-year period. However, the Indians had the secondbest winning percentage in the AL over that period, and finished second to the Yankees five times. In short, although the Indians only won the pennant twice, they were competing for 
the pennant nearly every year. Thus, they gained an advantage, relative to the rest of the AL, by employing black players.

Table 2 considers the immediate impact of integration in more detail. As the table shows, four of the six teams that integrated before 1952 were involved in their league's pennant race the following year. Of the two teams that did not see an immediate return on the investment in black players, the Boston Braves were involved in the pennant race in the third year after integrating; however, the St. Louis Browns never finished higher than fifth and suffered from poor funding and fan attendance. Both the Braves and the Browns were viewed as weak substitutes for their cross-town rivals.

Table 2 also shows that, as the theory of competitive markets would suggest, there is little to no impact from adding black players after 1952. Two reasons can be given for this

Table 2 Incidence of Initial Integration ${ }^{\mathrm{a}}$

\begin{tabular}{|c|c|c|c|c|}
\hline Player & Team & Date & $\begin{array}{l}\text { Year of } \\
\text { Integration }\end{array}$ & $\begin{array}{l}\text { Results after } \\
\text { integration }\end{array}$ \\
\hline \multicolumn{5}{|l|}{ (a) National League } \\
\hline Jackie Robinson & Brooklyn Dodgers & $4 / 15 / 1947$ & Won pennant & $\begin{array}{l}\text { Pennant race, pennant, } \\
\text { pennant race, } \\
\text { pennant }\end{array}$ \\
\hline $\begin{array}{l}\text { Monte Irvin and } \\
\text { Hank Thompson }\end{array}$ & New York Giants & $7 / 8 / 1949$ & Finished 5th & $\begin{array}{l}\text { Pennant race, pennant, } \\
\text { pennant race }\end{array}$ \\
\hline Sam Jethroe & Boston Braves & $4 / 18 / 1950$ & $\begin{array}{l}\text { Finished } 4 \text { th, } \\
\text { pennant race }\end{array}$ & $\begin{array}{l}\text { Finished } 4 \text { th, } 6 \text { th, } \\
\text { pennant race }\end{array}$ \\
\hline Ernie Banks & Chicago Cubs & $9 / 17 / 1953$ & Finished 7th & $\begin{array}{l}\text { Finished } 7 \text { th, 6th, } \\
\text { and } 8 \text { th }\end{array}$ \\
\hline Curt Roberts & Pittsburgh Pirates & $4 / 13 / 1954$ & Finished 8th & $\begin{array}{l}\text { Finished 8th in the } \\
\text { following three } \\
\text { seasons }\end{array}$ \\
\hline Tom Alston & St. Louis Cardinals & $4 / 13 / 1954$ & Finished 6th & $\begin{array}{l}\text { Finished } 7 \text { th, } 4 \text { th, } \\
\text { pennant race }\end{array}$ \\
\hline $\begin{array}{r}\text { Nino Escalera \& } \\
\text { Chuck Harmon }\end{array}$ & Cincinnati Reds & $4 / 17 / 1954$ & Finished 5th & $\begin{array}{l}\text { Finished 5th, 3rd, } \\
\text { and 4th }\end{array}$ \\
\hline John Kennedy & Philadelphia Phillies & $4 / 22 / 1957$ & Finished 5th & Finished 8th \\
\hline \multicolumn{5}{|l|}{ (b) American League } \\
\hline Larry Doby & Cleveland Indians & $7 / 5 / 1947$ & Finished 4th & $\begin{array}{l}\text { Pennant, pennant race, } \\
\text { pennant race }\end{array}$ \\
\hline Hank Thompson & St. Louis Browns & $7 / 17 / 1947$ & Finished 8th & $\begin{array}{l}\text { Finished } 6 \text { th, } 7 \text { th, } \\
\text { and } 5 \text { th }\end{array}$ \\
\hline Minnie Miñoso & Chicago White Sox & $5 / 5 / 1951$ & $\begin{array}{l}\text { Finished } 4 \text { th, } \\
\text { pennant race }\end{array}$ & $\begin{array}{l}\text { Pennant race in } 5 \\
\text { of next } 6 \text { years }\end{array}$ \\
\hline Bob Trice & Philadelphia Athletics & $9 / 13 / 1953$ & Finished 7 th & $\begin{array}{l}\text { Finished 8th, 6th, } \\
\text { and 8th }\end{array}$ \\
\hline Carlos Paula & Washington Senators & $9 / 6 / 1954$ & Finished 6th & $\begin{array}{l}\text { Finished 8th, 7th, } \\
\text { and 8th }\end{array}$ \\
\hline Elston Howard & New York Yankees & $4 / 14 / 1955$ & Won pennant & $\begin{array}{l}\text { Won pennant in all } \\
\text { three seasons }\end{array}$ \\
\hline Ozzie Virgil, Sr. & Detroit Tigers & $6 / 6 / 1958$ & Finished 5th & $\begin{array}{l}\text { Finished 4th, 6th, } \\
\text { and 2nd }\end{array}$ \\
\hline Pumpsie Green & Boston Red Sox & $7 / 21 / 1959$ & Finished 5 th & $\begin{array}{l}\text { Finished } 7 \text { th, 6th, } \\
\text { and } 8 \text { th }\end{array}$ \\
\hline
\end{tabular}

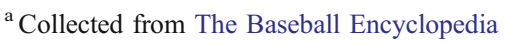


observation. First, there is a diminishing return to hiring additional black players, especially given that the Negro League disbanded in 1948. Most of the black players being brought to MLB were trained in the same minor leagues as the white players. Second, we would expect the best quality players to have already been acquired by the early integrators. Given the nature of team against team competition, if you want to improve your relative position through the addition of players, the players you hire must be better than the players your opponents hire.

\subsection{Why were NL teams more willing to integrate?}

One issue of importance is why integration occurred more quickly in the NL relative to the $\mathrm{AL}$, especially given the potential cost of reduced attendance if integration did not yield an increase in wins. It is our contention that the difference in the initial relative competitiveness of the leagues was the driving factor behind the speed with which consumers changed their discriminatory behavior toward black players. We measure each league's relative competitiveness by calculating the standard deviation of winning percentages for each year. In a 154-game season, the standard deviation for perfect competitive balance should be 0.040 (Scully 1992). The closer the actual standard deviation is to this idealized number, the more competitive the league will be.

As there was no interleague play at the time and the seasons consisted of the same number of games and scheduling breakdown, we can test to see whether there are any differences in relative competitiveness between the AL and the NL. If the two leagues have the same relative competitiveness, then teams in both leagues would have similar incentive to innovate through integration. If one league is relatively more competitive than the other, then teams in the more competitive league might be more willing to integrate than those in the less competitive league. The logic here is straightforward. In the more competitive league, integration provides a potential means of gaining a short-term advantage over others. In the less competitive league, in contrast, the potential payoff to integration is smaller. In the latter case, the chances of competing with the top team are lower, whereas the chances of alienating fans due to integration are higher.

As Table 3 illustrates, the standard deviation of winning percentage for the two leagues shows a marked difference in the level of competitive balance.

Table 3 Standard Deviation of Winning Percentage by League, 1945-1956 ${ }^{\text {a }}$

\begin{tabular}{lll}
\hline Year & AL & NL \\
\hline 1945 & 0.074 & 0.115 \\
1946 & 0.111 & 0.092 \\
1947 & 0.080 & 0.080 \\
1948 & 0.122 & 0.070 \\
1949 & 0.123 & 0.089 \\
1950 & 0.126 & 0.082 \\
1951 & 0.102 & 0.086 \\
1952 & 0.095 & 0.117 \\
1953 & 0.114 & 0.112 \\
1954 & 0.147 & 0.097 \\
1955 & 0.111 & 0.075 \\
1956 & 0.100 & 0.086 \\
\hline
\end{tabular}

a Authors' calculations, collected from The Baseball Encyclopedia

Springer 
In most years, the NL had a greater degree of competition than the AL, as evidenced by a lower standard deviation. A paired two-sample $t$ test reveals that the standard deviation of winning percentage in the AL is statistically greater than that in the NL over this period, at the $5 \%$ significance level.

The Austrian theory of entrepreneurship provides one means of explaining the existence of integration in one league compared to the other. Integration made sense when the reward tied to that innovation was more likely to be realized. Owners in the NL-where the variation in winning percentage was smaller - had an incentive to integrate because the reward for productive innovation would be realized relatively quickly. This was because of the fact that integration made them more competitive immediately. In other words, the potential gain from integration outweighed the potential negative consequences of alienating consumers with a taste for discrimination.

The AL owners, in contrast, with a greater amount of variation in the competitive level, saw less potential benefit to adding black players. Specifically, between 1947 and 1956 the Yankees won 8 of 10 AL Pennants. If, as previous studies suggest, consumers respond to a team involved in a pennant race, then adding a black player in the AL, while adding wins, will not move a team any closer to the pennant race for most teams. The Cleveland Indians, who finished second to the Yankees from 1951 to 1953 and again in 1955 and 1956, were the exception in the AL because they were the ones who had the most to gain by integratingi.e., they could beat the Yankees.

\section{Conclusion}

We have explored how the entrepreneurial process tends to erode economic errors associated with discrimination. It may appear that the market process is effective in correcting the inefficiencies associated with employer and co-worker discrimination, but not effective in correcting the inefficiencies associated with consumer preferences as consumers reward producers for satisfying these preferences. However, we have offered an explanation for how the entrepreneurial process can also overcome errors associated with consumer discrimination by revealing latent demands and the costs associated with those preferences.

Acknowledgment We would like to thank Ron Baker, Peter Boettke and Peter Leeson for useful comments. Christopher Coyne acknowledges the financial assistance of the Mercatus Center.

\section{References}

Becker, G. (1957). The economics of discrimination. Chicago: The University of Chicago Press.

Block, W. (1998). Compromising the uncompromisable. American Journal of Economics and Sociology, 57 (2), 223-237.

Ekelund, R. B., \& Saurman, D. S. (1988). Advertising and the market process: A modern economic view. Pacific Research Institute.

Fort, R. (2006). http://www.rodneyfort.com. Last accessed June 23.

Goff, B. L., McCormick, R. E., \& Tollison, R. D. (2002). Racial innovation as an innovation: Empirical evidence from sports leagues. American Economic Review, 92(1), 16-26.

Gwartney, J., \& Haworth, C. (1974). Employer costs and discrimination: The case of baseball. Journal of Political Economy, 82(4), 873-881.

Hanssen, A. (1998). The cost of discrimination: A study of major league baseball. Southern Economic Journal, 64(3), 603-627. 
Henderson, W. D. (2002). Demography and desegregation in the Cleveland public schools: Toward a comprehensive theory of educational failure and success. New York University Review of Law \& Social Change, 26, 457-568.

Kahn, L. M. (2000). The sports business as a labor market laboratory. Journal of Economic Perspectives, 14 (3), 75-94.

Kirzner, I. (1973). Competition and entrepreneurship. Chicago: The University of Chicago Press.

Leeds, M., \& von Allmen, P. (2005). The economics of sports (2nd ed.). Boston: Pearson Education, Inc.

Leeson, P. T., Coyne, C. J., \& Boettke, P. J. (2006). Does the market self correct? Asymmetrical adjustment and the structure of economic error. The Review of Political Economy, 18(1), 79-90.

Scully, G. W. (1992). The market structure of sports. Chicago and London: The University of Chicago Press.

Shmanske, S. (2007). Austrian themes, data, and sports economics. The Review of Austrian Economics, 20 (1), 11-24.

The Baseball Encyclopedia (1974). New York: Macmillan Publishing Co., Inc. 